\title{
EDITORIAL
}

\section{Are Countries Fulfilling the Promise They Made to Prevent Non- Communicable Diseases (NCDs)?}

\section{Abraham Haileamlak, MD, Professor of Pediatrics and Child Health}

As a result of behavioral, social and economic changes, NCDs affected all countries, but their burden and impact is worse on the poor and vulnerable populations. The World Health Organization (WHO) estimates that NCDs kill more than 38 million people annually which accounts for $68 \%$ of global deaths. More than 16 million (40\%) people, $90 \%$ of them in low-and middle-income countries die too young before the age of 70 years $(1,2)$. Besides the burden on the health care system, these premature deaths lead to economic losses. WHO estimates the cumulative economic losses due to NCDs in low- and middleincome countries to be 7 trillion USD during 20112025 if they do not focus on prevention which outweighs the annual 11.2 billion USD cost of implementing a high-impact interventions to reduce the NCD burden (3).

Reducing the global burden of NCDs is an overriding priority and a necessary condition for sustainable development. In 2011, at a the United Nations high-level meeting on NCDs, heads of state and government formally recognized NCDs as a major threat to economies and societies, and they agreed to address the global burden of NCDs (4). In order to transform this into action, the Sixty-sixth World Health Assembly adopted the Global action plan for the prevention and control of NCDs 2013-2020 with a comprehensive global monitoring framework, including a set of nine voluntary global targets. The voluntary global targets for prevention and control of NCDs to be attained by 2025 are:

1. A $25 \%$ relative reduction in the overall mortality from cardiovascular diseases, cancer, diabetes or chronic respiratory diseases;

2. At least $10 \%$ relative reduction in the harmful use of alcohol, as appropriate, within the national context;

3. A $10 \%$ relative reduction in prevalence of insufficient physical activity;

4. A $30 \%$ relative reduction in mean population intake of salt/sodium;

5. A $30 \%$ relative reduction in prevalence of current tobacco use

6. A $25 \%$ relative reduction in the prevalence of raised blood pressure or contain the prevalence of raised blood pressure, according to national circumstances;
7. A halt in the rise in diabetes and obesity;

8. At least $50 \%$ of eligible people receiving drug therapy and counselling (including glycemic control) to prevent heart attacks and strokes;

9. An $80 \%$ availability of the affordable basic technologies and essential medicines, including generics, required to treat major NCDs in both public and private facilities.

However, from my gross observation, many of the low and middle income countries are still overstretched with prevalent communicable diseases with little focus to NCDs.

The current issue (Vol. 27, No 3), the third regular issue for the year, contains one editorial, ten original articles and three case reports. The editorial, five of the original articles and one of the case reports are focus on NCDs. The other articles and case reports covered various topics.

I invite readers to read through these articles and appreciate or utilize the contents. I also encourage readers to forward comments and suggestions to the editor or the corresponding authors.

\section{REFERENCES}

1. World Health Organization. Global action plan for the prevention and control of noncommunicable diseases 2013-2020. WHO;Geneva; 2013.

2. World Health Organization.Global strategy for prevention and control of noncommunicable diseases. WHO Geneva: 2000.

3. World Health Organization. From burden to "best buys": reducing the economic impact of noncommunicable diseases in low- and middleincome countries. Geneva: World Health Organization and World Economic Forum; 2011.

4. Resolution 66/2. Political Declaration of the Highlevel Meeting of the General Assembly on the Prevention and Control of Non-communicable Diseases. In: Sixty-sixth session of the United Nations General Assembly. New York: United Nations; 2011.

DOI: http://dx.doi.org/10.4314/ejhs.v27i3.1 